Vol 12, Issue 8, 2019

\title{
FORMULATION AND EVALUATION OF OINTMENT CONTAINING SUNFLOWER WAX
}

\author{
AVISH D MARU*, SWAROOP R LAHOTI \\ Department of Pharmaceutics, Maulana Azad Educational Trust's Y. B. Chavan College of Pharmacy, Aurangabad, Maharashtra, India. \\ Email: avish.maru@gmail.com
}

Received: 22 March 2019, Revised and Accepted: 19 June 2019

ABSTRACT

Objective: The objective of the present work was to formulate and evaluate ointment using sunflower wax.

Methods: In the present work, ointment formulations were prepared using sunflower wax by fusion technique. Sunflower wax base was compared with standard base for its $\mathrm{pH}$, appearance, strength, spreadability, water number, and washability. Further, the optimized formulation was prepared with $2 \%$ salicylic acid and evaluated for its physicochemical parameters, compatibility study, drug content, in vitro drug diffusion, ex vivo permeability, and skin irritation test using rat skin.

Results: All of the prepared formulations of ointments were evaluated for its physicochemical parameters and all the findings obtained were within the prescribed limit. As compared to the ointment prepared by prototype formulae as per USP and IP, the formulation F3 containing $97 \%$ white petrolatum and $3 \%$ of sunflower wax showed good viscosity, strength, and spreadability. Based on viscosity, strength, and spreadability, formulation F3 was chosen as an optimized formulation.

Conclusion: The ointment consisting of white petroleum base $97 \%$ and $3 \%$ sunflower wax can be used for topical and systemic delivery of active ingredient salicylic acid. The results showed that sunflower wax can be used in ointment base as far as its pharmaceutical properties are concerned. It can effectively replace comparatively costlier available ointment bases.

Keywords: Ointment, Salicylic acid, Sunflower wax, Strength, Spreadability.

(C) 2019 The Authors. Published by Innovare Academic Sciences Pvt Ltd. This is an open access article under the CC BY license (http://creativecommons. org/licenses/by/4. 0/) DOI: http://dx.doi.org/10.22159/ajpcr.2019.v12i8.33199

\section{INTRODUCTION}

A number of topical dermatologic products, ranging from solids to liquids, are available for the treatment of skin diseases [1,2]. Majority of ointments consist of a base, which mainly acts as a carrier or vehicle for the medicaments. The nature of the base also controls its performance; hence, selection of ointment base is a very important aspect of formulation [3]. Traditional ointment bases have been oleaginous in nature, which include hydrocarbons such as petrolatum, beeswax, and vegetable oils that do not allow inclusion of any water inversely to fatty alcohols. Ointments are used topically for several purposes such as protective, antiseptic, emollient, antipruritic, keratolytic, and astringent. The base of an ointment is of prime importance if the finished product is expected to function as any of the above categories. The ointment base composition determines not only the extent of penetration but also controls the transfer of medicaments from the base to the body tissues $[3,4]$.

Many waxes such as white wax, carnauba wax, beeswax, and Candelilla wax are the natural waxes commonly used in cosmetic and pharmaceutical products [5]. Compared to these waxes, sunflower wax is cheap and obtained from natural source and is abundantly available. Sunflower wax is a hard, white crystalline, high melting point vegetable wax and is Ecocert Certified [6,7]. It is a component of the hull of sunflower (Helianthus annuus) oilseeds. The wax is composed of extensively saturated esters of long chain fatty acids (C20-C22) and fatty alcohols (C22-C29). It is often generated as a by-product of sunflower oil refinery and hence considered as of low economic value. It largely contains ceryl cerotate. It helps to thicken the formulation by providing a rigid structural network of wax crystals, improving oil binding, emolliency, film formation, and lubricity $[8,9]$. Therefore, an attempt has been made in the present study to utilize sunflower wax substituting beeswax in ointment bases with functional benefits in the formulation of ointments.

\section{MATERIALS AND METHODS}

\section{Materials}

The sunflower wax was obtained as a gift sample from M/s Mahesh Ltd., Mumbai, India. All other chemicals were used of analytical grade.

\section{Methods}

Compatibility study

The differential scanning calorimetry (DSC) thermograms of salicylic acid, sunflower wax, white petrolatum, and optimized formulation were recorded on DSC Lab: Mettler Instrument. For analysis, all samples (2-4 mg) were weighed accurately into a tared standard aluminum pans and sealed using an aluminum lid. Analysis was carried out over a temperature range of $0-240^{\circ} \mathrm{C}$ with a heating rate of $10^{\circ} \mathrm{C} / \mathrm{min}$ in a nitrogen gas environment (30 $\mathrm{mL} / \mathrm{min})$ [10].

\section{Preparation of ointment formulations}

Two topical ointment bases of varying degrees of aqueous or anhydrous character, namely: simple ointment USP (T1) and simple ointment IP (T2) and formulations containing sunflower wax were prepared by fusion method [10-12]. In this method, the constituents of the base were placed together in a melting pan and allowed to melt together at $70^{\circ} \mathrm{C}$. After melting, the ingredients were stirred gently maintaining temperature of $70^{\circ} \mathrm{C}$ for about $5 \mathrm{~min}$ and then cooled with continuous stirring to $40^{\circ} \mathrm{C}$. Ointments were then stirred until a smooth consistency was obtained and stored at room temperature $\left(25^{\circ} \mathrm{C}\right)$ and used for further analysis. Formulation of ointment containing $2 \%$ salicylic acid was done by incorporating $2 \mathrm{~g}$ of the drug into the optimized formulation F3 by triturating on an ointment slab with spatula to obtain $100 \mathrm{~g}$. The composition of all ointment formulations is presented in Table 1. 


\section{Evaluation of ointment}

All the prepared ointments were characterized for the parameters such as appearance, odor, color, homogeneity, $\mathrm{pH}$, spreadability, hardness, water number, and viscosity measurements.

\section{Organoleptic characteristics}

All blank formulations (i.e., formulations without active ingredient) and drug-loaded formulation were tested for physical appearance, color, texture, phase separation, and homogeneity. These characteristics were evaluated by visual observation. Homogeneity and texture were tested by pressing a small quantity of the formulated cream and gels between the thumb and index finger. The consistency of the formulations and the presence of coarse particles were used to evaluate the texture and homogeneity of the formulations. Immediate skin feel (including stiffness, grittiness, and greasiness) was also evaluated [13,14].

\section{PH}

About $2.5 \mathrm{~g}$ of all formulations were taken in dry beaker and $50 \mathrm{ml}$ of water was added. Beaker containing ointments was heated on water bath at $60-70^{\circ} \mathrm{C}$. The $\mathrm{pH}$ of ointments determined using a $\mathrm{pH}$ meter $\mathrm{pH}$ Tutor, Eutech Instruments). The determinations were carried out in triplicate and the averages of three readings were noted.

\section{Spreadability}

Spreadability of the formulation was determined by an apparatus suggested by Multimer with some modifications [15]. It consists of a wooden block having a pulley at one end with fixed glass slide on block. An excess of ointment $(3 \mathrm{~g})$ placed on ground plate. The ointment was sandwiched between this plate and another glass plate having the dimension of fixed ground plate and provided with the hook. A $1 \mathrm{~kg}$ weight was placed on the top of the two plates for $5 \mathrm{~min}$ to expel air and to provide a uniform film of the ointment between the plates. Excess of ointment was scrapped off from the edges. The top plate was then subjected to pull of $240 \mathrm{~g}$. With the help of spring attached to the hook and time required by the top plate to cover a distance of $10 \mathrm{~cm}$ was noted. A shorter interval indicates better spreadability. Spreadability was calculated using the following formula:

\section{$\mathrm{S}=\mathrm{M} \times \mathrm{L} / \mathrm{T}$}

Where, $\mathrm{S}=$ Spreadability

$\mathrm{M}=$ Weight in the pan (tied to the upper slide)

$\mathrm{L}=$ Length moved by the glass slide and

$\mathrm{T}=$ Time (in seconds) taken to separate the slide completely each other.

\section{Viscosity}

Brookfield Synchro-Lectric Viscometer (Model RVT) with Helipath Stand was used for rheological studies. The sample $(50 \mathrm{~g})$ was placed in a beaker and was allowed to equilibrate for 5 min before measuring the dial reading using a T-D spindle at 10, 20, 30, 50, 60, and $100 \mathrm{rpm}$. At each speed, the corresponding dial reading on the viscometer was noted. The spindle speed was successively lowered and the corresponding dial reading was noted. The measurements were carried in triplicate at ambient temperature. Direct multiplication of the dial readings with factors given in the Brookfield Viscometer catalog gave the viscosity in centipoises (CPS).

\section{Water number}

Water number is the maximum amount of water that can be added to $100 \mathrm{~g}$ of base at a given temperature. It was determined by continuously stirring the base with the addition of distilled water. When no more water was absorbed into the base evidenced by droplets of water, remaining in the container was taken as end point.

\section{Hardness/strength}

Hardness of formulations was determined using Texture Pro CT V1.3 (Build 15 Brookfield Engineering Labs, Inc.) texture analyzer. It is based on the speed of the displacement of probe into sample (ointment) at a given distance. The probe was moving down at a speed of $2 \mathrm{~mm} / \mathrm{s}$ till a $7 \mathrm{~g}$ surface trigger was attained. At this point, the probe was in full contact with the sample surface. Then, the probe continued to penetrate to a depth of $4 \mathrm{~mm}$ at a speed of $2 \mathrm{~mm} / \mathrm{s}$. At this point, the probe returned to its starting position. The penetration depth of a standard $4 \mathrm{~mm}$ needle $(\mathrm{P} / 2 \mathrm{~N})$ at a constant $10 \mathrm{~kg}$ load force was measured to represent the hardness of the formulation. The peak load (maximum force) was registered and is considered a measure of firmness of the product - the bigger the force the thicker/harder is the sample. All tests were conducted 2 times at room temperature $\left(25 \pm 2^{\circ} \mathrm{C}\right)$ and values of peak force were expressed in $\mathrm{g}$.

\section{Drug content}

Content of salicylic acid in the formulation was determined by diluting $1 \mathrm{~g}$ of ointment equivalent to $2 \mathrm{mg}$ of drug in $10 \mathrm{ml}$ of ethanol and volume was made up to $100 \mathrm{ml}$ with $\mathrm{pH} 7.4$ phosphate buffer. Absorbance was measured at $275 \mathrm{~nm}$ using ultraviolet (UV)-visible spectrophotometer and percentage drug content was calculated and average of three determinations was noted $(\mathrm{n}=3)[12]$

\section{In vitro diffusion study}

Franz diffusion cell was used for the drug release studies. Ointment was evenly applied onto the surface of cellulose membrane. The cellulose membrane was clamped between the donor and the receptor chamber of diffusion cell. The receptor compartment was filled with phosphate buffer $\mathrm{pH} 7.4$, and the assembly was maintained at $37^{\circ} \mathrm{C} \pm 0.5$ under constant magnetic stirring. With reference to Scale-up and Post-approval Changes guidelines laid by FDA, $300 \mathrm{mg}$ of ointment was applied to the membrane on the donor compartment and then covered with aluminum foil to prevent drying out. Aliquots were withdrawn at predetermined time intervals over a period of $1 \mathrm{~h}$ and amount of salicylic acid released was analyzed at $275 \mathrm{~nm}$ using UV spectrophotometer $[12,16,17]$.

\section{Ex vivo permeation study}

The rat skin was used by cleaning with a mild skin cleanser, removing any hair and subdermal fat and fascia were used. The prepared rat skin was mounted on the Franz diffusion cell (with effective diffusion area $3.14 \mathrm{~cm}^{2}$ and $7 \mathrm{ml}$ cell volume) with stratum corneum facing upward. The receptor compartment was filled with phosphate buffer $\mathrm{pH} 7.4$, and the assembly was maintained at $37^{\circ} \mathrm{C} \pm 0.5$ under constant magnetic stirring. The amount of drug permeated through rat skin was carried out as per method described in diffusion study [16-18].

Table 1: Composition of ointment formulations containing sunflower wax

\begin{tabular}{|c|c|c|c|c|c|c|c|c|}
\hline \multirow[t]{2}{*}{ Ingredients (\%) } & \multicolumn{8}{|c|}{ Formulation code } \\
\hline & IP (T1) & USP (T2) & F1 & F2 & F3 & F4 & F5 & F3 - SA* \\
\hline White petrolatum & 85 & 95 & 95 & 96 & 97 & 98 & 99 & 97 \\
\hline White beeswax & - & 5 & - & - & - & - & - & - \\
\hline Sunflower wax & - & - & 5 & 4 & 3 & 2 & 1 & 3 \\
\hline Wool fat & 5 & - & - & - & - & - & - & - \\
\hline Hard paraffin & 5 & - & - & - & - & - & - & - \\
\hline Cetostearyl alcohol & 5 & - & - & - & - & - & - & - \\
\hline
\end{tabular}

*Optimized ointment formulation $\mathrm{F} 3$ with $2 \%$ salicylic acid 
Skin irritation study

Healthy albino rats of 25-30 g body weight were used for skin irritancy and sensitization model. The animals were housed in polypropylene cages and maintained under standard conditions (12 h light and dark cycles, at $22 \pm 2{ }^{\circ} \mathrm{C}$ and $35-60 \%$ humidity). Standard palletized feed and tap water were provided ad libitum. The study was approved by the Institutional Animal Ethical Committee of R. C. Patel Institute of Pharmaceutical Education and Research, Shirpur, India, registered under Committee for the Purpose of Control and Supervision of Experiments on Animals (CPCSEA), India (registration No. 951/09/C/CPCSEA).

This test was performed on albino rats weighing between 150 and 200 g. Animals are divided into four groups, each batch containing five animals. Dorsal hairs at the back of the rats were removed 1 day before the commencement of the study and kept individually in cages to avoid contact with the other rats. Optimized formulation F3-SA containing sunflower wax, USP (T1), and IP (T2) simple ointments was used to compare the skin irritation study on rats. Two groups of each were used for control and standard irritant. Other two groups were used as test. The $50 \mathrm{mg}$ of each formulation were applied over one square centimeter area of whole and abraded skin of different animals. Aqueous solution of $0.8 \%$ formalin was used as standard irritant. At the end of the study, animal skin was evaluated for the skin irritancy and sensitization effect. The animals were observed for 7 days for any signs of edema and erythema. The photographs were taken and evaluated for the skin irritancy [19].

\section{Stability testing}

The developed ointment formulations were subjected to stability study as per the International Conference on Harmonization (ICH) guidelines. The formulated ointment was filled in the collapsible tubes and stored at different temperatures and humidity conditions, namely, $25^{\circ} \mathrm{C} \pm 2^{\circ} \mathrm{C} \quad / 60 \% \pm 5 \% \mathrm{RH}, \quad 30^{\circ} \mathrm{C} \pm 2^{\circ} \mathrm{C} / 65 \% \pm 5 \% \mathrm{RH}$, and $40^{\circ} \mathrm{C} \pm 2{ }^{\circ} \mathrm{C} / 75 \% \pm 5 \% \mathrm{RH}$ for a period of 3 months and studied for appearance, $\mathrm{pH}$, viscosity, and spreadability $[19,20]$.

\section{RESULTS AND DISCUSSION}

\section{Compatibility study}

DSC analysis was performed for salicylic acid, sunflower wax, and optimized formulation F3-SA. DSC thermogram showed a distinct melting endotherm of drug and sunflower wax at $160^{\circ} \mathrm{C}$ and $80^{\circ} \mathrm{C}$ with an enthalpy value of $-366.69 \mathrm{~J} / \mathrm{g}$ and $-1207.56 \mathrm{~J} / \mathrm{g}$, respectively. Figs. 1-3 represent thermograms of salicylic acid, sunflower wax, and optimized formulation selected for the study. Melting endotherm of drugs was well preserved in most of the cases. For optimized formulation, in all the cases, melting endotherm of drug was well preserved with little or no change in enthalpy value of drug, indicating compatibility of drug with selected excipients in the study.

\section{Physical evaluation of ointments \\ Organoleptic characteristics}

The organoleptic properties, including physical appearance, color, texture, phase separation, homogeneity, and immediate skin feel of the ointment formulations, are shown in Table 2. Results showed that the ointments had a good appealing appearance and smooth texture, and they were all homogenous with no signs of phase separation. All formulations were white in color and aromatic odor

$\mathrm{pH}$

$\mathrm{pH}$ of all formulations was found to be between $6.80 \pm 0.152$ and $7.02 \pm 0.174$ that is within the range, which are presented in Table 3. The $\mathrm{pH}$ of all formulations lies in the normal $\mathrm{pH}$ range of the skin.

\section{Viscosity}

Viscosity of all the formulations was noted and found in the range of $2314 \pm 6.13-2851 \pm 9.93 \mathrm{CPS}$ at $10 \mathrm{rpm}$ as shown in Table 3. All

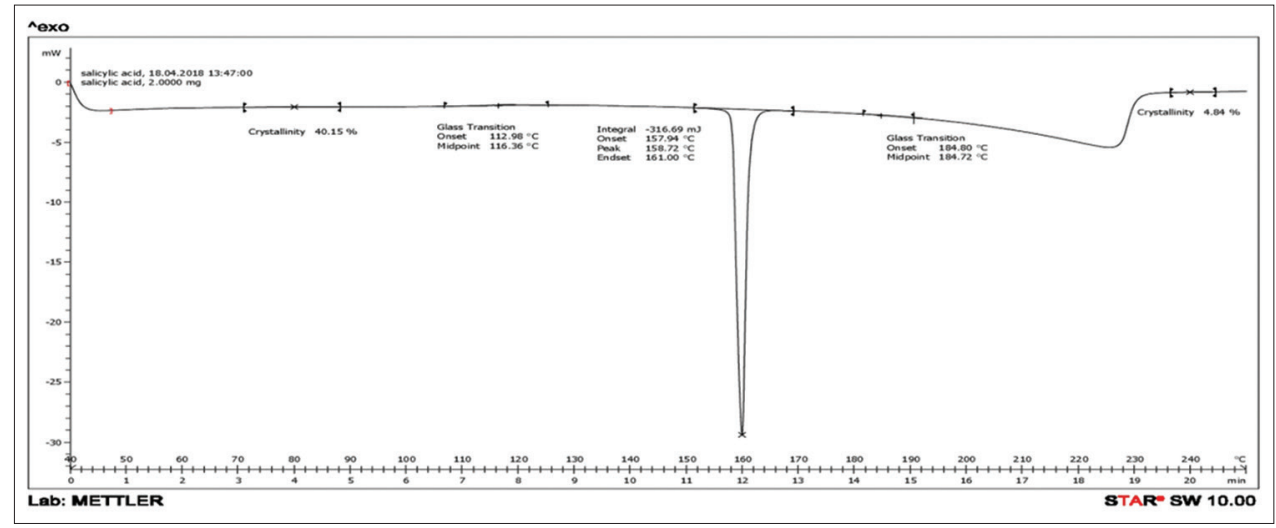

Fig. 1: Differential scanning calorimetry thermogram of salicylic acid

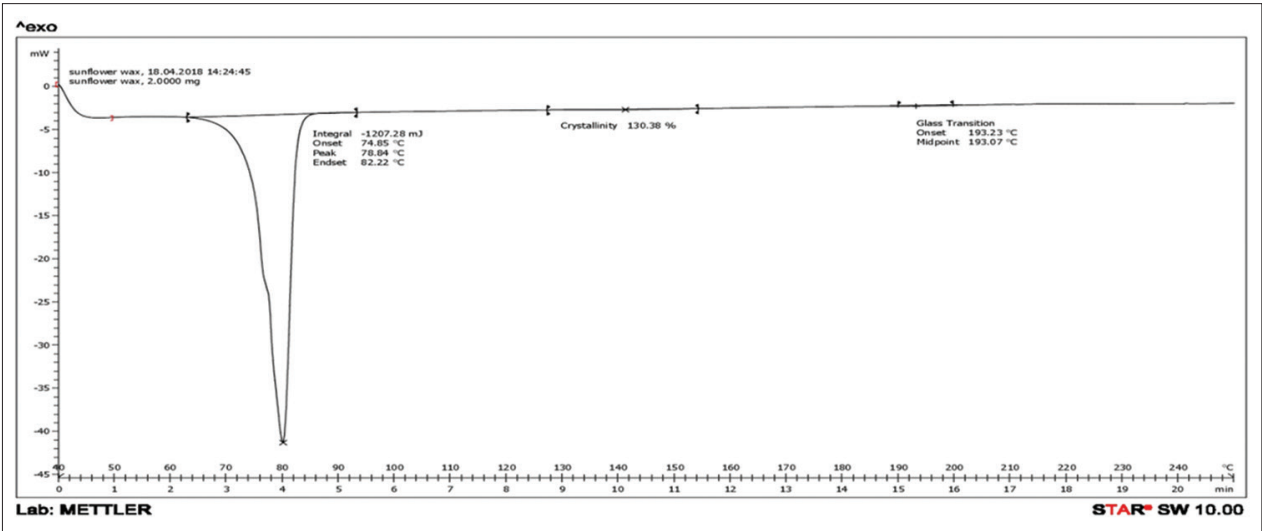

Fig. 2: Differential scanning calorimetry thermogram of sunflower wax 


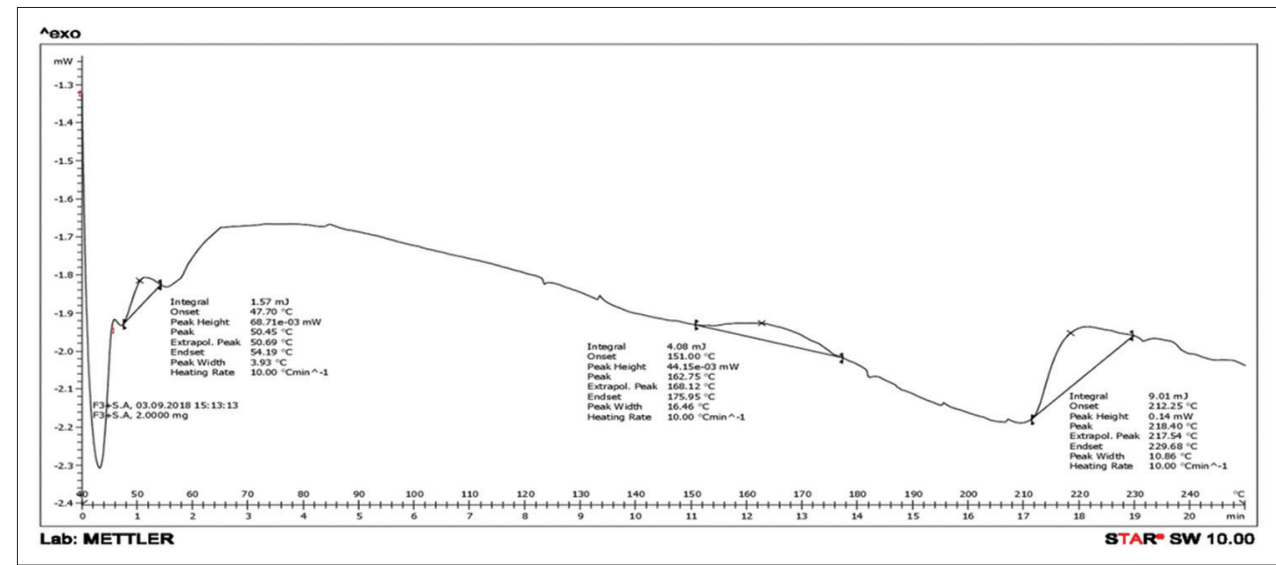

Fig. 3: Differential scanning calorimetry thermogram of optimized formulation F3-SA

Table 2: Physicochemical evaluation of ointment formulations

\begin{tabular}{|c|c|c|c|c|c|}
\hline $\begin{array}{l}\text { Formulation } \\
\text { code }\end{array}$ & $\begin{array}{l}\text { Physical } \\
\text { appearance }\end{array}$ & Texture & $\begin{array}{l}\text { Phase } \\
\text { separation }\end{array}$ & Homogeneity & Immediate skin feel \\
\hline USP (T1) & Opaque & Smooth & No & Homogeneous & No grittiness or greasiness \\
\hline IP (T2) & Opaque & Smooth & No & Homogeneous & No grittiness or greasiness \\
\hline F1 & Opaque & Rough and hard & No & Homogeneous & No grittiness or greasiness \\
\hline $\mathrm{F} 2$ & Opaque & Smooth & No & Homogeneous & Little grittiness was observed and no greasiness \\
\hline F3 & Opaque & Smooth & No & Homogeneous & No grittiness or greasiness \\
\hline $\mathrm{F} 4$ & Opaque & Smooth & No & Homogeneous & No grittiness or greasiness \\
\hline F3 - SA* & Opaque & Smooth & No & Homogeneous & No grittiness or greasiness \\
\hline
\end{tabular}

*Optimized ointment formulation F3 with $2 \%$ salicylic acid

Table 3: Evaluation parameters of ointment formulations

\begin{tabular}{|c|c|c|c|c|c|c|}
\hline $\begin{array}{l}\text { Formulation } \\
\text { code }\end{array}$ & pH $(\text { mean } \pm S D)^{\#}$ & $\begin{array}{l}\text { Viscosity at } 10 \\
\operatorname{rpm}(C P S)(\text { mean } \pm S D)^{\#}\end{array}$ & $\begin{array}{l}\text { Spreadability } \\
\text { g.cm/s (mean } \pm S D)^{\#}\end{array}$ & $\begin{array}{l}\text { Hardness (g) } \\
(\text { mean } \pm S D)^{\#}\end{array}$ & $\begin{array}{l}\text { Water } \\
\text { number }(\text { mean } \pm S D)^{\#}\end{array}$ & $\begin{array}{l}\text { Drug } \\
\text { content (\%) }\end{array}$ \\
\hline USP (T1) & $7.00 \pm 0.195$ & $2456 \pm 6.53$ & $97.32 \pm 4.53$ & $128 \pm 4.50$ & $1.1 \pm 0.14$ & - \\
\hline IP (T2) & $7.02 \pm 0.174$ & $2489 \pm 8.95$ & $102.91 \pm 5.03$ & $148 \pm 6.93$ & $1.5 \pm 0.16$ & - \\
\hline $\mathrm{F} 1$ & $6.80 \pm 0.152$ & $2851 \pm 9.93$ & $80.00 \pm 3.83$ & $243 \pm 4.13$ & $1.2 \pm 0.25$ & - \\
\hline $\mathrm{F} 2$ & $7.01 \pm 0.185$ & $2612 \pm 8.13$ & $109.09 \pm 5.13$ & $220 \pm 3.90$ & $1.3 \pm 0.08$ & - \\
\hline F3 & $6.90 \pm 0.189$ & $2472 \pm 7.23$ & $112.57 \pm 4.23$ & $157 \pm 3.83$ & $1.3 \pm 0.12$ & - \\
\hline F4 & $6.92 \pm 0.244$ & $2412 \pm 8.03$ & $110.16 \pm 3.53$ & $138 \pm 4.13$ & $1.4 \pm 0.10$ & - \\
\hline F3-SA* & $6.89 \pm 0.196$ & $2470 \pm 7.33$ & $102.91 \pm 4.13$ & $154 \pm 5.83$ & $1.4 \pm 0.19$ & $99.63 \pm 4.10$ \\
\hline
\end{tabular}

\#All values are mean \pm SD of three determinations. SD: Standard deviation. *Optimized ointment formulation F3 with $2 \%$ salicylic acid

the formulations were showed pseudoplastic flow. Average of three readings was calculated and standard deviation was determined $(n=3)$.

\section{Spreadability}

Ointment spreadability can be categorized into three groups: Low, moderate, and high. After screening, it was found to be inversely proportional to the concentration of sunflower. As the amount of sunflower wax increased, the ointment became thicker, and, consequently, spreadability decreased. The spreadability of all formulations was determined and it was observed that formulation F3 has greater spreadability as compared to other formulations as well as prototype formulations USP (T1) and IP (T2) as shown in Table 3.

\section{Hardness}

Hardness test is indicative of strength of ointment formulations and the results are found in the range of $122 \pm 5.03-243 \pm 4.13 \mathrm{~g}$. It is observed that hardness of the ointment base formulated increases with increase in sunflower wax. This indicates that the proportion of the sunflower wax must be well controlled in the formulation for optimal hardness because when the product is too hard, spreadability will be difficult, and thus, the efficacy will be retarded. Optimized formulation F3 showed closed strength such as prototype formulations USP (T1) and IP (T2) represented in Table 3.
In vitro drug diffusion study

The in vitro release profile using salicylic acid as model drug from ointment diffusion cell showed that $94.34 \%$ of drug was released at the end of $1 \mathrm{~h}$ represented in Fig. 4 .

Ex vivo permeation study

The results of drug permeation through rat skin reveal that drug was released continuously through rat skin over a period of $1 \mathrm{~h}$. The F3SA formulation with $3 \%$ of sunflower wax showed drug permeation of $82.57 \pm 1.25$ at the end of $1 \mathrm{~h}$ study represented in Fig. 5 .

Skin irritation study

Optimized ointment formulation did not show any sign of erythema or edema when applied topically to the skin of animals during the study period. Formulation F3-SA and standard base formulations were found to be safe as they do not cause redness of skin and get score 0 .

Stability study

All the ointment formulations were subjected to stability study as per ICH guidelines and results are shown in Table 4. During the stability studies, the appearance of formulations was clear and no significant variation in $\mathrm{pH}$, spreadability, viscosity, and drug content for optimized formulation for the period of 3 months. 
Table 4: Stability study of optimized formulation F3-SA

\begin{tabular}{llllll}
\hline S. No. & Observation & $\begin{array}{l}\text { Before stability } \\
\text { testing*(mean } \pm \text { SD) }\end{array}$ & \multicolumn{3}{l}{ After stability testing*(mean \pm SD) } \\
\cline { 5 - 6 } & & $6.59 \pm 0.96$ & 1 month & 2 months & 3 months \\
\hline 1. & pH & $2470 \pm 6.96$ & $6.49 \pm 0.91$ & $6.69 \pm 0.13$ & $6.79 \pm 0.12$ \\
2. & Viscosity & $98.90 \pm 2.32$ & $2472 \pm 7.45$ & $2476 \pm 7.96$ & $2470 \pm 06.23$ \\
3. & Drug content & $102.91 \pm 4.12$ & $99.19 \pm 3.25$ & $98.09 \pm 2.25$ & $99.89 \pm 1.24$ \\
4. & Spreadability & & $101.25 \pm 3.92$ & $102.52 \pm 2.56$ & $102.25 \pm 3.20$ \\
\hline
\end{tabular}

*All values are mean \pm SD of three determinations. SD: Standard deviation

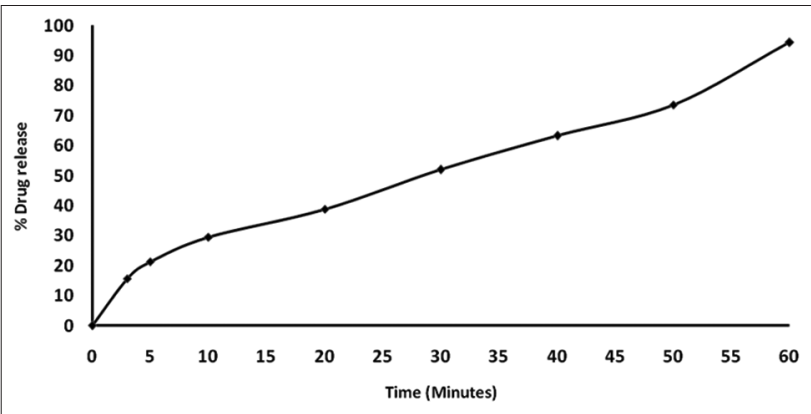

Fig. 4: Percentage cumulative amount of salicylic acid diffused from ointment formulation through cellulose membrane using Franz diffusion cell

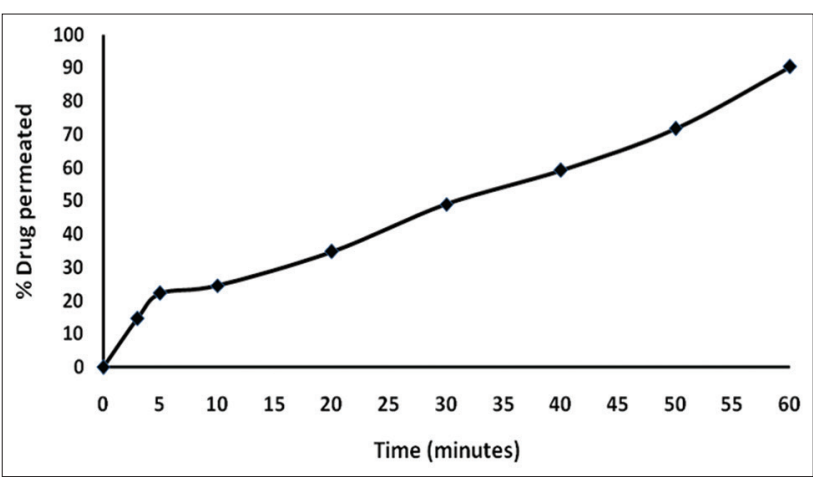

Fig. 5: Percentage cumulative amount of salicylic acid permeated from ointment formulation through rat skin using Franz diffusion cell

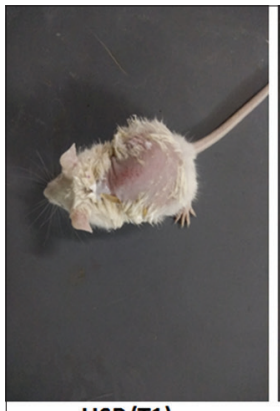

USP(T1)

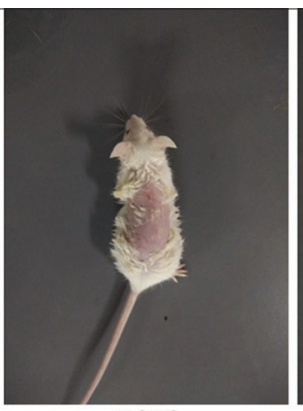

IP (T2)

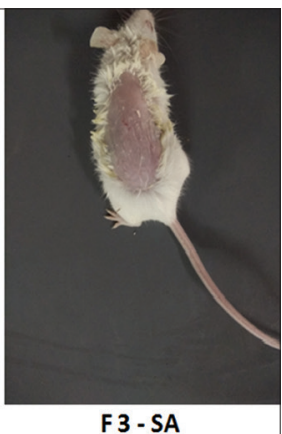

F 3 - SA
Fig. 6: Skin irritation study of optimized formulation F3-SA in comparison with standard ointment base formulations

\section{DISCUSSION}

Prepared ointment formulations were subjected to various assessment parameters and the findings obtained were within the prescribed limits which are depicted in Tables 2 and 3. pH of all the formulations was found to be alkaline. All the formulations showed pseudoplastic flow on the basis of viscosity. The spreadability of formulation F3 is greater as compared to other formulations as well as the prototype formulations. It is seen that overall spreadability was improved by decreasing the concentration of sunflower wax. The formulation F3 prepared with sunflower wax was selected as optimized formulation on the basis of results of spreadability, viscosity, and hardness. The salicylic acid was used as model drug and incorporated in optimized formulation F3 and showed promising results for in vitro drug diffusion and ex vivo permeation through cellulose membrane and rat skin, respectively. Formulation F3-SA was subjected to skin irritation study on rats showed no signs of redness when compared with standard base formulations USP (T1) and IP (T2) as shown in Fig. 6. Stability study indicates that optimized formulation is stable for the period of 3 months.

\section{CONCLUSION}

This study reveals that replacement of white beeswax with sunflower wax did not alter the properties of the simple ointment, thereby providing an economical alternative to beeswax. In general, we can say that sunflower wax is indigenous vegetable wax which is not commonly used so far but can successfully replace to other traditional natural hard waxes such as carnauba and beeswax in pharmaceutical and cosmetic products. It is seen that ointment containing a sunflower wax with active ingredient showed good strength, viscosity, and spreadability with no signs of skin irritation on rat skin. It also reduced the quantity of hard wax required in the ointment as compared to beeswax. Thus, it could be effective to incorporate sunflower wax in ointment formulations, to avail of its economical and functional benefits. It is anticipated, this work will encourage more research and faith toward utilization of natural active ingredients in pharmaceuticals.

\section{ACKNOWLEDGMENTS}

The authors are thankful to M/s Mahesh India Ltd., Mumbai, for providing gift sample of sunflower wax. Authors are delighted to say thanks to the principal and management of Maulana Azad Educational Trust's Y. B. Chavan College of Pharmacy, Aurangabad, MS, India, for support and providing necessary facilities to carry out the research work successfully.

\section{AUTHORS' CONTRIBUTIONS}

Experimental design, guidance, supervision, and review work for the research were done by Dr. Swaroop R. Lahoti. Experimental work, development and optimization of the formulations, interpretation of result, and writing of this manuscript were done by Mr. Avish D. Maru. Both authors read and approve the final manuscript.

\section{CONFLICTS OF INTEREST}

We declare that we have no conflicts of interest.

\section{REFERENCES}

1. Rawlings AV, Harding CR. Moisturization and skin barrier function. Dermatol Ther 2004;17 Suppl 1:43-8.

2. Marty JP. NMF and cosmetology of cutaneous hydration. Ann Dermatol Venereol 2002;129:131-6.

3. Cravello B, Ferri A. Relationships between skin properties and environmental parameters. Skin Res Technol 2008;14:180-6.

4. Cancalon P. Chemical composition of sunflower seed hulls. J Am Oil Chem Soc 1971;486:29-32, 12 
5. Morrison WH. Variation in the wax content of sunflower seeds with location and hybrids. J Am Oil Chem Soc 1983;60:1013-5.

6. Ayerbe R. A study on the recovery of byproducts from the dewaxing of sunflower oils of national production. Grasas Aceites 1985;36:1-4

7. Wannee J. Review of nutraceutical uses of an antioxidant sunflower sprouts. Asian J Pharm Clin Res 2016;9:21-3.

8. Mariani C. Minor components of vegetable oils: Non-glyceridic esters. Riv Ital Sostanze Grasse 1989;66:397-401.

9. Carelli AA. Wax composition of sunflower seed oils. J Am Oil Chem Soc 2002;79:763-8.

10. Sharma PP. Cosmetics-formulation, Manufacturing and Quality Control, Cap. 7. $5^{\text {th }}$ ed. Delhi, India: Vandana Publications; 2014. p. 181-91.

11. Rowe RC, Sheskey PJ, Weller PJ. Handbook of Pharmaceutical Excipients. London: Pharmaceutical Press; 2003.

12. Bhalekar M, Manish L, Krishna S. Formulation and evaluation of rice bran wax as ointment base. Anc Sci Life 2004;24:52-5.

13. Lachman L, Herbert AL, Joseph LK. The Theory and Practice of Industrial Pharmacy, Chp 3. India: Varghese Publication House; 1999. p. 569.
14. Kilor V, Sapkal N, Vaidya G. Design and development of novel microemulsion based topical formulation of hesperidin. Int J Pharm Pharm Sci 2015;7:142-8.

15. Multimer M. Spreadability determination by an apparatus. J Am Pharm Assoc 1956;45:212-4.

16. Dua D, Srivastava NS. Study on antioxidant and anti-aging properties of few medicinal plants. Int J Pharm Pharm Sci 2016;8:344-7.

17. Ayobami OO, Okikiolu OJ, Hannah OO, Samuel OO. Ocular tolerance and in-vitro release of chloramphenicol in prospective eye ointment bases. Int J Pharm Pharm Sci 2015;7:306-11.

18. Pattanayak S, Nayack SS, Dinda SC, Panda D, Naval KP. Evaluation of herbal ointments formulated with methanolic extract of Cajanus scarabaeoides. J Pharm Allied Health Sci 2011;2:47-59.

19. Daniels R, Knie U. Galenics of dermal products vehicles, properties and drug release. J Dtsch Dermatol Ges 2007;5:367-83.

20. Suchiwa PO, Soravoot R, Ounaroon A, Kongkaew C, Tiyaboonchaia W. Development, characterization and skin irritation of mangosteen peel extract solid dispersion containing clay facial mask. Int J Appl Pharm 2018;10:202-8. 